\title{
DESIGUALDAD Y PODER EN GUATEMALA: ECONOMÍA DE CAPTURA. HARALD WAXENECKER. GUATEMALA: PARAÍSO DESIGUAL, 2019
}

Guillermo Díaz

\author{
Recibido: 16/06/19 - Aceptado: 24/06/19
}

El libro en mención es una lectura indispensable, por no decir obligada, para comprender la historia contemporánea de Guatemala, en especial la causa de la lucha ciudadana, iniciada en 2015, contra la corrupción. El tema central del libro describe con datos históricos y estadísticos la lógica del alto nivel de corrupción imperante en el país, materializado a través de la captura del Estado. El libro constituye también un referente en el campo de la economía de captura, tanto en su enfoque metodológico, basado en análisis de redes y de regresión, como en sus hallazgos, que son ilustrativos del fenómeno de captura del Estado que experimenta Guatemala.

La originalidad y gran valor del libro radica en el análisis de casi 300000 datos, de un período de trece años, para obtener los resultados. El método utilizado para dicha obtención se explica con claridad e incluso se ejemplifica, lo que brinda una mejor comprensión al lector.

Otro aspecto valioso del libro es la contextualización que realiza de la economía guatemalteca, en especial de los cambios en su estructura durante los tres primeros lustros del presente siglo XXI, así como de la mayor concentración de la riqueza producida por el país, por parte de las grandes empresas. Este fenómeno crea las condiciones para la captura del Estado de Guatemala, según sostiene el autor.

De forma sintetizada el libro permite una aproximación teórica y metodológica a la economía de captura. En muy poco texto describe los principales índices para medir el fenómeno de la corrupción y de la captura del Estado, resaltando que Guatemala se ubica en ranking bajos en los índices, en particular en los temas de Estado de Derecho y corrupción. La lectura del apartado teórico permite comprender de qué trata la economía de captura. En concreto, estudia los mecanismos utilizados por los agentes económicos para obtener ventajas y ganancias extraordinarias, al margen de la competencia de mercado. 
Entre las formas en que se concretiza la captura del Estado está la compra que el mismo realiza de bienes y servicios a agentes económicos privados. Este es el campo de análisis delimitado por el autor, a través de 298927 licitaciones realizadas en el período 2004 a 2017, que abarca cuatro gobiernos diferentes. Las licitaciones comprenden áreas de infraestructura, salud, alimentos, transporte y seguridad, por un monto acumulado de casi 103000 millones de quetzales, equivalente a 1.2 veces el presupuesto nacional de 2019. Otro dato importante es que en las licitaciones participaron un poco más de 10000 empresas y 1200 instituciones gubernamentales.

El análisis de redes sociales es utilizado para identificar el grado de intermediación y conectividad entre los actores participantes en las licitaciones, es decir, empresas e instituciones gubernamentales. El grado de intermediación mide la capacidad de actuar como enlace entre actores dispersos en el entramado de las licitaciones. La conectividad expresa la vinculación que empresas tienen con mismos compradores. A partir del grado alto o bajo de intermediación y gubernamental, el autor establece las siguientes cuatro categorías: Máximo rendimiento, donde ambas dimensiones de análisis tienen valores altos; Rendimiento mínimo, con valores bajos en las dos variables; Grupo cohesivo, con alta intermediación y baja conectividad; y Grupo desintegrado, con baja intermediación y alta conectividad.

La clasificación de las empresas según su grado de intermediación y conectividad permitió clasificar a la mayoría de las empresas en las categorías Grupo cohesivo y Rendimiento mínimo.

El grado de intermediación y conectividad son utilizadas como variables explicativas de la variable monto adjudicado, en la regresión que calculada por el autor para estimar el potencial económico, el cual al restarlo del valor adjudicado de las licitaciones permite estimar el valor capturado. En otras palabras, permite estimar el monto capturado del mercado, que a su vez sirve para estimar el beneficio extraordinario obtenido, mediante el ejercicio de influencias de las empresas. Los cálculos también permiten estimar el incentivo comercial monetario o soborno recibido por las instituciones gubernamentales.

Los diagramas con que el autor ilustra el monto de los contratos adjudicados contra el monto potencial que se pudo adjudicar, son útiles para visualizar la magnitud del tráfico de influencias ejercido por las empresas captoras.

Los resultados obtenidos revelan que en el mercado de infraestructura, que es el de mayor valor, con 78000 millones de quetzales, equivalente al $90 \%$ del presupuesto nacional de 2019, en el período analizado, de 2004 a 2017, la economía de captura pudo haber comprendido el $35 \%$ del total de contratos y $64 \%$ del valor total de los mismos. Durante los diferentes gobiernos de esos años, menos del $20 \%$ de las empresas participantes obtuvieron las adjudicaciones. Lo anterior fue posible a través de la configuración de redes entre pocas empresas privadas e instituciones gubernamentales. 
Con base en información pública obtenida de procesos judiciales contra empresas descubiertas en casos de corrupción, el autor describe el entramado de la captura del Estado y el mecanismo para el pago del incentivo comercial monetario o soborno, cuyo monto oscilaba entre $5 \%$ y $15 \%$.

El análisis de la economía de captura del sector de infraestructura se desglosa a nivel centralizado o nacional y descentralizado o local. El autor también describe la parte del mercado capturado por las categorías Grupo cohesivo y Rendimiento mínimo. El mayor porcentaje de valor capturado corresponde a pocas grandes empresas.

El siguiente sector analizado por el autor fue el de salud. El patrón de captura se repite en dicho sector. Del total de contratos, $44 \%$ fueron objeto de captura y el monto capturado fue de $52 \%$. Lo mismo sucede en el sector de alimentos, combustibles y los otros sectores analizados.

El estudio realizado revela que en los diferentes sectores el valor de sobornos y excedente de captura o beneficio extraordinario ascendió a alrededor de $20 \%$ del valor total de los contratos, divido casi en partes iguales entre los dos actores participantes en las licitaciones, instituciones de gobierno y empresas privadas. Aproximadamente fueron mil, de diez mil empresas proveedores, las involucradas en captura del Estado, en especial de gran tamaño. En algunos casos es posible conocer nombres de empresas y montos capturados. En tal sentido, el libro es explícito en detalles para conocer una parte de la captura del Estado de Guatemala.

Guillermo Díaz. Guatemalteco. Doctor en Sociología, profesor en la Universidad Rafael Landívar. Sus publicaciones incluyen un análisis de redes de la élite económica guatemalteca y de la concentración de los mercados en Guatemala.

Contacto: godiaz@url.edu.gt

ORCID: 000-0002-2522-9851 
